\title{
Research of the determination method of furfurals and furosine in milk and the application in the quality evaluation of milk
}

\author{
Xiaomei Shi ${ }^{1}$, Qiong $\mathrm{Wu}^{2}$, Dandan Ren ${ }^{1}$, Shuya Wang ${ }^{1}$, Yunfeng Xie ${ }^{1 *}$ \\ ${ }^{1}$ COFCO Nutrition and Health Research Institute, Beijing Key Laboratory of Nutrition Health and Food Safety, Beijing, \\ People's Republic of China; ${ }^{2}$ Laboratory of Jiangxi Province for Persistent Pollutants Control and Resources Recycle, \\ Nanchang Hang Kong University, Nanchang, People's Republic of China; ${ }^{3}$ Institute of Quality Standard \& Testing \\ Technology for Agro-Products, Key Laboratory of Agro-Product Quality and Safety, Chinese Academy of Agricultural \\ Sciences, Beijing, China
}

"Correspondence Author: Yunfeng Xie, No. 4 Road, Future Science and Technology Park South, Beiqiiia, Changping, Beijing 102209, China. Email: xieyunfeng@cofco.com

Received: 16 July 2021; Accepted: 21 December 2021; Published: 26 January 2022

(c) 2022 Codon Publications

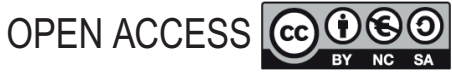

ORIGINAL ARTICLE

\begin{abstract}
The heat treatment process usually affects the quality and safety of milk and could produce different compounds, including furosine and furfurals. To help evaluate the effect of different heating temperatures on furfurals, a method based on gas chromatography-mass spectrometry (GC-MS) combined with QuEChERS (quick, easy, cheap, effective, rugged, and safe) extraction technology was used to detect four furfural compounds, including furfural, 2-acetylfuran, 5-methyl-2-furfural, and 5-hydroxymethyl-2-furfural. A sample extraction was performed with acetonitrile, and the use of both octadecylsilyl (C18) and primary secondary amine (PSA) sorbents can provide satisfactory recoveries. The determination of furosine was performed by using a high performance of liquid chromatography method (HPLC), and the milk samples were hydrolyzed with $\mathrm{HCl}$ for $18 \mathrm{~h}$ at $110^{\circ} \mathrm{C}$. Under the optimized conditions, good linearity was obtained with linear correlation coefficients $\left(R^{2}\right)$ above 0.99 , and the recovery values from the spiked samples were $88.1-109.5 \%$. The limits of detection were in the range of 0.005 $\mathrm{mg} / \mathrm{kg}-0.015 \mathrm{mg} / \mathrm{kg}$. The established GC-MS and HPLC methods were successfully applied to market milk samples and heat-treatment samples. The highest detection values for 5-hydroxymethyl-2-furfural and furosine were $0.051 \mathrm{mg} / \mathrm{kg}$ and $593.2 \mathrm{mg} / 100$ g protein, respectively, in charcoal-flavored fermented milk. It showed a high correlation between the formation of 5-hydroxymethyl-2-furfural with the treatment temperature and time, and the maximum content was $0.886 \mathrm{mg} / \mathrm{kg}$ after heating for $180 \mathrm{~min}$ at $100^{\circ} \mathrm{C}$. However, there was no noticeable linear increase of furosine concentrations when certain temperatures and heating times were reached; the maximum value was $55.0 \mathrm{mg} / \mathrm{L}$ after heating for $60 \mathrm{~min}$ at $100^{\circ} \mathrm{C}$, and $55.4 \mathrm{mg} / \mathrm{L}$ after heating for $150 \mathrm{~min}$ at $80^{\circ} \mathrm{C}$.
\end{abstract}

Keywords: 5-hydroxymethyl-2-furfural; furosine; GC-MS; milk; heat process; sterilization

\section{Introduction}

Milk products are rich in protein, fat, lactose, minerals, and vitamins, which are the best sources of calcium for human health. With the improvement in living standards, milk products have become a nutritious food that is important and essential for consumers. As a "national beverage," the quality and safety of milk products has received more attention in recent years (Sakkas et al., 2014). However, milk products as a type of heat-processed food can experience the Maillard reaction between the carbohydrates and proteins, which is also known as 
a "nonenzymatic browning reaction." The Maillard reaction leads to a decrease in milk product nutrients, which is mainly divided into the initial stage, middle stage, and final stage (Cortés et al., 2018). Furosine, as a marker product in the initial stage of the Maillard reaction, is usually thought to be an indicator of heat damage, and it can be used to identify whether reconstituted milk is added into fresh milk (Ferrer et al., 2003; Lan et al., 2010; Sunds et al., 2018).

During the sterilization process of milk products, different furfural compounds will be produced, which include 5-hydroxymethyl-2-furfural (5-HMF) and furfural (F). Furfural compounds have attracted more attention because their content can reflect the sterilization processing temperatures of milk products (Chávez et al., 2006; Wherry et al., 2019). The study of 5-HMF in milk products has received special attention because it has been found to exhibit mutagenic and DNA strand-breaking activity, and there are many reports about the cytotoxic, genotoxic, mutagenic, and carcinogenic effects of 5-hydroxymethyl-2-furfural (Abraham et al., 2011; Chavez-Servin et al., 2015; Giovanelli and Cappa, 2021). Notably, 5-HMF is produced when the temperature is high, and the higher the temperature, the higher the production of 5-HMF. Dr. Xing reported that the initial content of 5 -HMF in UHT was $0.37 \mathrm{mg} / \mathrm{kg}$ following 5 days of storage at a high temperature of $60^{\circ} \mathrm{C}$, and the value increased to $0.74 \mathrm{mg} / \mathrm{kg}$ (Xing et al., 2021). The Codex Alimentarius of the World Health Organization and the European Union have established a maximum quality level of $40 \mathrm{mg} / \mathrm{kg}$ in honey and $50 \mathrm{mg} / \mathrm{kg}$ in apple juice for 5 -HMF. However, there is no relevant limits standard in milk products for 5 -HMF. Therefore, analytical methods with good applicability, high accuracy, and high sensitivity for the determination of furfural compounds, particularly 5 -HMF in milk products, are in great demand.

At present, the detection methods of furosine in milk products mainly include high performance liquid chromatography (HPLC) (Cho et al., 2012; Gómez-Narváez et al., 2017; Mayer et al., 2010), ion pair chromatography (Tokusoglu et al., 2006), and capillary zone electrophoresis (Bignardi et al., 2012; Delgado-Andrade et al., 2005). These methods all take a certain approach that involves acid hydrolysis, which can lead to unreliable repeatability and inaccuracy of the determination results (Cattaneo et al., 2008; Sabater et al., 2018). However, few papers reported using advanced technology, such as the quadrupole-orbitrap mass spectrometry method and liquid chromatography coupled with tandem mass spectrometry (LC-MS/MS) because of expensive equipment (Liu et al., 2020; Poojary et al., 2019). Therefore, it is important to find the key factors affecting the detection results of furosine and to establish a more reliable method for the research of furosine. The traditional detection methods of the furfural compounds in milk products are ultraviolet spectrophotometry, micellar capillary electrophoresis, and derivatization spectrophotometry (Sun et al., 2017; Yang et al., 2012). Most of the methodologies currently applied to the analysis of furfurals in milk products are based on the HPLC method (Ferrer et al., 2005; Li et al., 2021). These classical techniques for the analysis of furfurals require extensive sample preparation, and the detection limits were high (Kalal et al., 2007; Masoumeh et al., 2015; Mesías-García et al., 2010). In recent years, mass spectrometry methods have been applied to the monitoring of furfurals; for example, a method using LC-MS with an atmospheric pressure chemical ionization (APCI) source for the analysis of 5-HMF has been published (Gokmen et al., 2006). The gas chromatography-mass spectrometry (GC-MS) method (PiñeiroGarcía et al., 2018), as well as the gas chromatography coupled with triple quadrupole mass spectrometry (GCMS/MS) method, are also optimal options to ensure the unequivocal identification and quantification of furfural compounds in milk products (Cui et al., 2020; Teixidó et al., 2006).

The aim of the present work was to develop and validate a GC-MS method for the simultaneous determination of four furfural compounds-furfural (F), 5-methyl-2-furfural (MF), 2-acetylfuran (FMC), and 5-hydroxymethyl-2-furfural (5-HMF)-in milk products. The sample was prepared using the modified QuEChERS method. This method should provide effective guidance for the establishment of the limit standards of 5-HMF in milk products. We determined furosine using the standard hydrolysis method, and the critical hydrolysis time was determined in our research. Quality parameters were established, and the proposed methods were successfully applied to the determination of 5-HMF and furosine in the milk samples. Both of the established GC-MS and HPLC methods save time and cost. The determination results of the two compounds can be used to evaluate the quality of dairy products, which are important indicators for the effects of processing temperature on quality.

\section{Materials and Methods}

\section{Reagents and materials}

Furosine dihydrochloride with purity $>98.0 \%$ was provided by the Alta Scientific Corporation (Tianjin, China). In addition, 5-HMF with purity $>97.8 \%$, MF with purity $>99.6 \%$, and $\mathrm{F}$ with purity $>99.5 \%$ were obtained from Dr. Ehrenstorfer GmbH (Augsburg, Germany), and FMC with purity $>98.0 \%$ was provided by ANPEL Laboratory Technologies (Shanghai, China). Chromatographic grade acetonitrile was purchased from Sigma-Aldrich (Santa Clara, United States). Ultra-pure water was purified from 
a Milli-Q-Plus ultra-pure water system from Millipore Sigma (Millipore, Bedford, MA, United States). The analytical-grade reagents, including sodium acetate anhydrous, magnesium sulfate anhydrous $\left(\mathrm{MgSO}_{4}\right)$, hydrochloric acid, and ammonium acetate, were purchased from XiLong Scientific Co., Ltd. (Guangzhou, China), and the analytical reagent grade sodium chloride was from the China National Pharmaceutical Group Chemical Testing (Beijing, China). The primary secondary amine (PSA; 40-63 $\mu \mathrm{m}$, ultraclean bulk for QuEChERS) and $C_{18}(50 \mu \mathrm{m}$, ultraclean bulk for QuEChERS) were obtained from Agela Technologies (Shanghai, China). The casein, whey protein, and glucose were food grade and were purchased from Zhengzhou Longsheng Chemical Products Co., Ltd. (Zhengzhou, China).

\section{Instrumentation}

A gas chromatograph-mass spectrometry, model number 7890A-5975C, manufactured by Agilent Technologies Inc., was used in this study. The HPLC equipment was manufactured by Thermo Fisher Scientific, and its model number was U3000. The desktop high-speed centrifuge (Sorvall ST 16R Centrifuge), manufactured by Thermo Fisher Scientific, was used in this study. The MX-S mixer used in the extraction step was manufactured by the Wanshun Instrument Company (Jiangsu, China). The ultrasonic cleaner (SB-120 DTN) was from Ningbo Scientz Biotechnology Co., Ltd. (Ningbo, China), the samples for heat treatment analysis were obtained from a heated on-the-dry bath heater instrument, and the heating unit was made of aluminum blocks (SBH130D and SBH200D, Stuart Company, England).

\section{High performance of liquid chromatography}

The furosine was analyzed using the HPLC method. The mobile phase, which was degassed and filtered before analysis, consisted of $0.1 \%$ formic acid in water $\mathrm{A}$ and methanol B. The eluent flow rate was $1.0 \mathrm{~mL} / \mathrm{min}$ with the mobile phase initially consisting of $95 \% \mathrm{~A}$ and $5 \% \mathrm{~B}$, and then decreased linearly to $85 \%$ A from 0 min to 15 $\mathrm{min}$. This period held for $5 \mathrm{~min}$, from $15 \mathrm{~min}$ to $20 \mathrm{~min}$, and finally recovered to $95 \% \mathrm{~A}$ in $1 \mathrm{~min}$ and was held for $9.0 \mathrm{~min}$. The ultraviolet detection wavelength measurements were carried out at $280 \mathrm{~nm}$. All of the samples were separated in the column of an AQ-C18 $(4.6 \times 250$ $\mathrm{mm}, 5 \mu \mathrm{m}$, Welch ultimate, United States). The injection volume was $20 \mu \mathrm{L}$, and the temperature of the column oven was maintained at $40^{\circ} \mathrm{C}$. The HPLC chromatogram of furosine is shown in Figure 1.

\section{Gas chromatography-mass spectrometry}

The TG-5 MS (30 $\mathrm{m} \times 0.25 \mathrm{~mm}, 0.25 \mu \mathrm{m}$, Thermo Fisher, United States), cp-WAX $(50 \mathrm{~m} \times 0.25 \mathrm{~mm}, 0.25 \mu \mathrm{m}$, Agilent, United States), and Rtx-WAX (30 m ×0.25 mm, $0.25 \mu \mathrm{m}$, Shimadzu, Japan) were selected for the separation of the four furfural compounds. The carrier gas used was helium at a constant flow rate of $1.0 \mathrm{~mL} / \mathrm{min}$. The extract injected volume was $1 \mu \mathrm{L}$, and the injection mode was a split-less mode. The initial oven temperature was set at $60^{\circ} \mathrm{C}$ and held for $2 \mathrm{~min}$, then raised to $120^{\circ} \mathrm{C}$ at the rate of $20^{\circ} \mathrm{C}$ per minute. It finally increased to $220^{\circ} \mathrm{C}$ at $10^{\circ} \mathrm{C}$ per minute and was held for another $10 \mathrm{~min}$. The inlet temperature was $230^{\circ} \mathrm{C}$, the temperature of the transfer line was set to $250^{\circ} \mathrm{C}$, and the ion source temperature was $230^{\circ} \mathrm{C}$. The mass spectrometer was operated in electron ionization mode at $70 \mathrm{eV}$ with a selected ions monitoring mode (SIM), and the quadruple temperature was set at $150^{\circ} \mathrm{C}$. The data acquisition and analysis were performed using the software supplied by Agilent. The GC-MS chromatogram of a mixed standard solution of the four furfural compounds is shown in Figure 2A.

\section{Sample selection and heat treatment}

Different types of milk samples were purchased from retail stores for the analysis of furfural compounds and

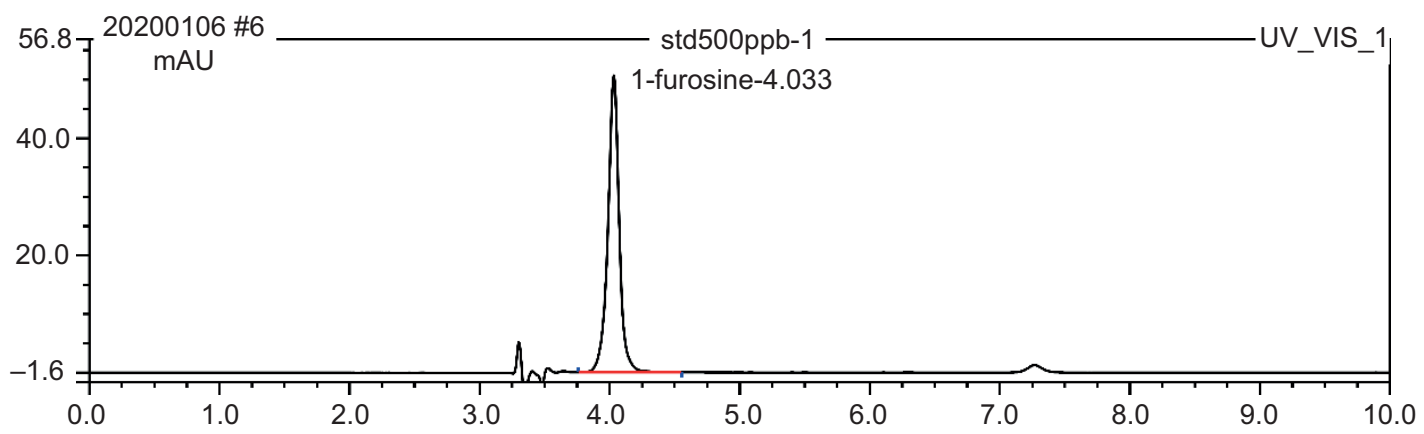

Figure 1. High performance of liquid chromatography chromatogram of furosine. 
(A)

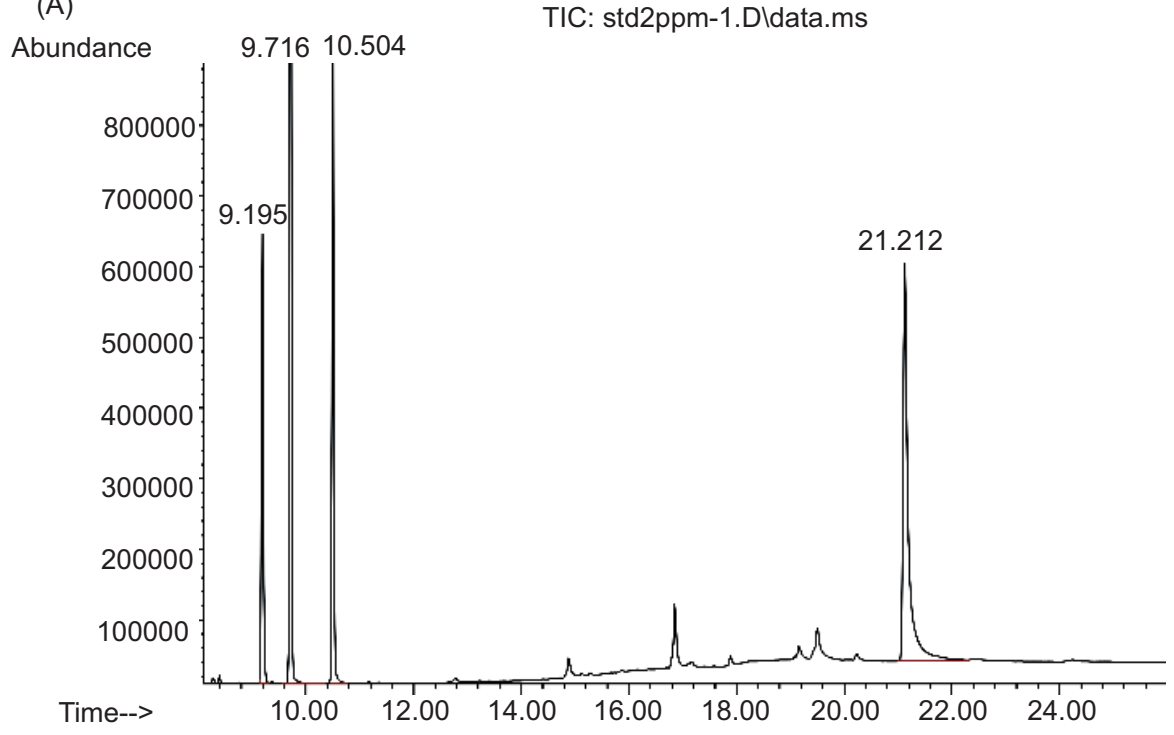

(B)

Abundance

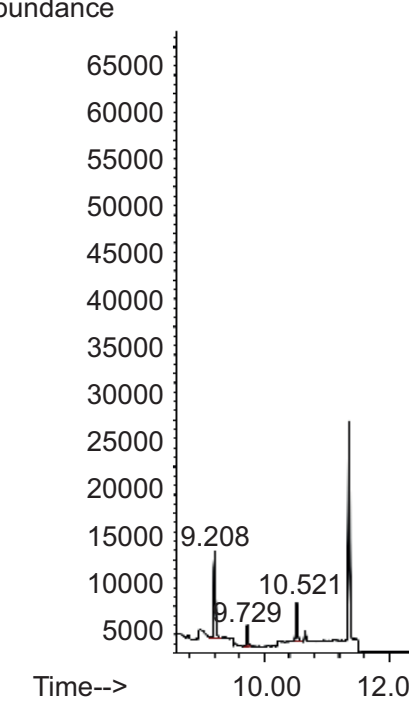

TIC: junlebao tanshao-1 Dldata.ms

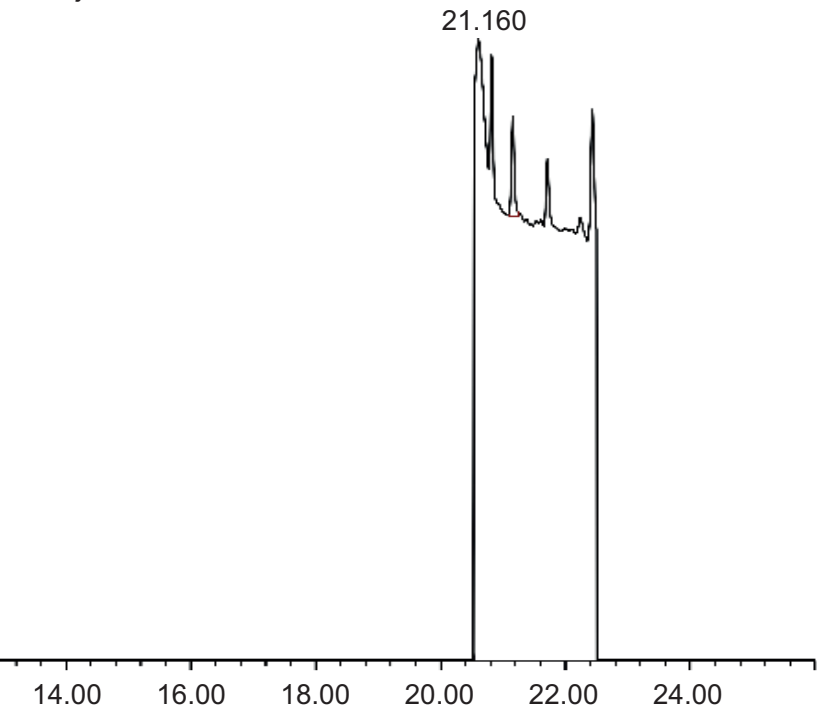

Figure 2. The gas chromatography-mass spectrometry chromatograms of furfural compounds standards solution and milk sample: (A) furfural compounds standards solution and (B) sample E5.

furosine. According to the sterilization condition, we selected low temperature pasteurized milk, high temperature pasteurized milk, and ultra-high temperature sterilization milk for research. The heat-treatment analysis samples were obtained artificially by mixing 2.8 $\mathrm{g}$ of casein, $0.7 \mathrm{~g}$ of whey protein, and $7.0 \mathrm{~g}$ of glucose in $100 \mathrm{~mL}$ of pure water. After the raw materials were mixed evenly, the different heat treatment times were set as $30 \mathrm{~min}, 45 \mathrm{~min}, 60 \mathrm{~min}, 90 \mathrm{~min}, 120 \mathrm{~min}, 150 \mathrm{~min}$, and $180 \mathrm{~min}$ by replacing a heating tube, and the temperatures were set at $25^{\circ} \mathrm{C}, 40^{\circ} \mathrm{C}, 60^{\circ} \mathrm{C}, 80^{\circ} \mathrm{C}$, and $100^{\circ} \mathrm{C}$, respectively. Samples were immediately taken after cooling at room temperature. The furosine content was detected using the HPLC method, and the 5-HMF content was determined using the GC-MS method.

\section{Sample preparation}

For the determination of furfural compounds, $5.0 \mathrm{~g}$ milk samples were mixed with $10 \mathrm{~mL}$ of acetonitrile (ACN) in $50 \mathrm{~mL}$ centrifuge tube and then thoroughly vortexed for $2 \mathrm{~min}$ to extract the furfural. Then, $3 \mathrm{~g}$ of sodium chloride $(\mathrm{NaCl})$ and $1 \mathrm{~g}$ of sodium acetate anhydrous (NaAc) were added, and the mixture was vortexed for $2 \mathrm{~min}$, followed by sonication for $20 \mathrm{~min}$. In addition, $3 \mathrm{~g}$ of magnesium 
sulfate anhydrous $\left(\mathrm{MgSO}_{4}\right)$ was added to the mixture to remove water, and the samples were centrifuged at 8000 x.g. for $5 \mathrm{~min}$. Then, $1 \mathrm{~mL}$ of supernatant was transferred to a $10 \mathrm{~mL}$ centrifuge tube and $40 \mathrm{mg}$ of $\mathrm{C}_{18}$ adsorbent, 10 mg of PSA adsorbent, and $100 \mathrm{mg}$ of $\mathrm{MgSO}_{4}$ were added, vortexed for $1 \mathrm{~min}$, and centrifuged for $5 \mathrm{~min}$ in $5000 \mathrm{x}$.g. The supernatant was filtered with a $0.22 \mu \mathrm{m}$ PTFE membrane and finally analyzed by GC-MS.

For the analysis of furosine, we accurately measured $2 \mathrm{~mL}$ of milk in a closed heat-resistant tube, added $6 \mathrm{~mL}$ of $10.6 \mathrm{~mol} / \mathrm{L}$ hydrochloric acid, and mixed well. The tube was put in a drying oven and heated at $110^{\circ} \mathrm{C}$ for hydrolysis. The test tube was shaken after hydrolysis for $1 \mathrm{~h}$, and the heating time was $18 \mathrm{~h}$. When the tube temperature cooled down, the hydrolysate sample was filtered and 1 $\mathrm{mL}$ was put in a $10 \mathrm{~mL}$ centrifuge tube, and $5 \mathrm{~mL}$ of 6 $\mathrm{g} / \mathrm{L}$ ammonium acetate solution was added. Finally, the hydrochloric acid solution was mixed well and filtered through a $0.22 \mu \mathrm{m}$ aqueous phase membrane and tested using the HPLC equipment.

\section{Results and Discussion}

\section{Optimization of GC-MS conditions}

The mass spectrogram of each furfural compound was obtained by full scan mass spectrogram, and one quantitative ion and one or two qualitative ions were selected for each compound, respectively. The quantitative and qualitative ions were selected according to the intensity of the ions, and the ions with the largest abundance were selected as the quantitative ions. According to the retention time of these compounds, the selective ion detection mode was carried out in different time periods, and the most important was to ensure that there was no interference between the detected compound ions in each time period. The parameters for the four furfural compounds are shown in Table 1.

Because the target compounds have aldehyde, ether, and ketone functional groups, three different chromatographic columns, including TG-5 MS, cp-WAX, and Rtx-WAX, were chosen to separate the furfural compounds. When the furfurals were separated on the TG-5
MS column, the results included serious tailing and poor separation efficiency, while the cp-WAX and Rtx-WAX chromatographic columns offered sharp peaks and high resolution. Between the two polar columns, we finally chose the cp-WAX column because it seemed that the four furfurals have higher intensity by the separation of cp-WAX column than that of the Rtx-WAX column.

\section{Optimization of samples preparation}

The hydrolysis procedure of furosine in milk samples was very critical, and we designed three different tests for the optimization of the hydrolysis procedure. The results were obtained by adding the furosine standard solutions to the milk samples, and each test was designed to check the sample without adding the furosine standard solutions. The samples' processing procedures were consistent with the description of sample preparation for the analysis of furosine. The hydrolysis time for test one was set to $6 \mathrm{~h}$, test two was set to $18 \mathrm{~h}$, and test three was set to $23 \mathrm{~h}$. When the hydrolysis procedure was finished, 1 $\mathrm{mL}$ of hydrolysate was taken as a sample. Test one and test two were added in $5 \mathrm{~mL}$ of a $6 \mathrm{~g} / \mathrm{L}$ ammonium acetate solution, and test three was added in $5 \mathrm{~mL}$ of a 3 $\mathrm{mol} / \mathrm{L}$ hydrochloric acid solution. The recovery result of test one was $59.92 \%$, test two was $83.73 \%$, and test three was $41.39 \%$. This revealed that the hydrolysis time should not be too long or too short; otherwise, this would affect the detection results of furosine.

\section{Linear range and detection limit}

For the method validation, mixed standard solutions of the four furfurals were prepared, and the standard curves of the four furfurals and furosine were prepared by plotting the concentration (represented by $\mathrm{x}$ ) on the abscissa and the peak areas (represented by y) on the ordinate. The linear calibration ranges, regression equations, and correlation coefficients of the furfurals and furosine are summarized in Table 2. The linear range was $0.05 \mathrm{mg} / \mathrm{L}-$ $2.0 \mathrm{mg} / \mathrm{L}$ for $5-\mathrm{HMF}$, and $0.01 \mathrm{mg} / \mathrm{L}-1.0 \mathrm{mg} / \mathrm{L}$ for the other three furfural compounds and furosine. The correlation coefficients $\left(R^{2}\right)$ were above 0.99 in all cases. The detection limits (LOD) of the four furfural compounds

Table 1. Mass spectrometric conditions for the four furfural compounds.

\begin{tabular}{llccr} 
Number & Name & Retention time (min) & Mass (m/z) & Quantitation mass \\
\hline 1 & Furfural (F) & 9.195 & $67,95,96$ & 96 \\
2 & 2-acetylfunan (FMC) & 9.710 & 95,110 & 95 \\
3 & 5-methyl-2-furfural (MF) & 10.504 & $81,109,110$ & 110 \\
4 & 5-hydroxymethyl-2 furfural (5-HMF) & 21.212 & $97,125,126$ & 97 \\
\hline
\end{tabular}


were in the range of $0.005 \mathrm{mg} / \mathrm{kg}-0.015 \mathrm{mg} / \mathrm{kg}$, and the detection limit of furosine was $0.02 \mathrm{mg} / \mathrm{L}$. The LOD values were determined as the concentrations at which the signal-to-noise ratio $(\mathrm{S} / \mathrm{N})$ was greater than three, and the limits of quantitation (LOQ) were determined as the concentrations at which the signal-to-noise ratio $(\mathrm{S} / \mathrm{N})$ was greater than 10 ; the results are shown in Table 3. The detection limits of this method were lower than the recently reported methods, including the HPLC and GC-MS methods, and we can fully guarantee the effective separation of the four furfural compounds under the established conditions.

\section{Recovery}

Milk samples without furfurals and furosine were weighed and spiked with mixed standard solutions at low, medium, and high concentrations. The spiked levels for the three furfurals were $0.05 \mathrm{mg} / \mathrm{kg}, 0.1 \mathrm{mg} / \mathrm{kg}$, and
$0.2 \mathrm{mg} / \mathrm{kg}$, and the spiked levels for furosine were 0.08 $\mathrm{mg} / \mathrm{L}, 0.82 \mathrm{mg} / \mathrm{L}$, and $1.63 \mathrm{mg} / \mathrm{L}$. Six parallel experiments were conducted at each concentration level, and the contents of the four furfurals were determined by GC-MS after pretreatment using the optimized QuEChERS method, and the contents of furosine were determined using the optimized HPLC method. The recovery values were also calculated, and the results showed that the average recoveries were in the range of $78.2-109.5 \%$, and the relative standard deviations were from 0.02 to $1.8 \%$, which proved that the proposed methods were accurate, reliable, and could meet the analysis requirements. The average recovery values and relative standard deviations (RSDs) are summarized in Table 3.

\section{Matrix effects}

There are many reports for the research of furfurals, particularly 5-HMF, and these reports always use mass

Table 2. Linear ranges, regression equations, correlation coefficients, and matrix effects evaluation of furfurals and furosine in milk products.

\begin{tabular}{lccccc} 
Compounds & Linear range/mg/L & Regression equation & $\mathbf{R}^{2}$ & ME evaluation & ME evaluation $^{\mathbf{b}}$ \\
\hline F & $0.01 \sim 1.0$ & $y=304 x$ & 0.9974 & $y=193.6 x$ & $y=211.5 x$ \\
FMC & $0.01 \sim 1.0$ & $y=1041 \mathrm{x}$ & 0.9984 & $y=563.6 \mathrm{x}$ & $\mathrm{y}=547.1 \mathrm{x}$ \\
MF & $0.01 \sim 1.0$ & $\mathrm{y}=377 \mathrm{x}$ & 0.9974 & $\mathrm{y}=267.3 \mathrm{x}$ & $\mathrm{y}=272.5 \mathrm{x}$ \\
5-HMF & $0.05 \sim 2.0$ & $\mathrm{y}=568 \mathrm{x}$ & 0.9953 & $\mathrm{y}=289.3 \mathrm{x}$ & $\mathrm{y}=292 \mathrm{x}$ \\
Furosine & $0.01 \sim 1.0$ & $\mathrm{y}=10.2 \mathrm{x}$ & 0.9995 & $\mathrm{y}=10.0 \mathrm{x}$ & $\mathrm{y}=10.1 \mathrm{x}$ \\
\hline
\end{tabular}

Note: The detection limit of furosine was $0.02 \mathrm{mg} / \mathrm{L}$.

ME was matrix effects, ME evaluation ${ }^{a}$ was gained in the liquid milk samples, and ME evaluation ${ }^{b}$ was gained in the flavored fermented milk.

Table 3. Recoveries, detection limits of furfurals and furosine in milk products $(n=6)$.

\begin{tabular}{|c|c|c|c|c|}
\hline Compounds & Spiked level/mg/kg & Recovery $/ \%$ (RSD/\%) & LOD (mg/kg) & $\mathrm{LOQ}(\mathrm{mg} / \mathrm{kg})$ \\
\hline \multirow[t]{3}{*}{$\mathrm{F}$} & 0.05 & $88.1(1.4)$ & & \\
\hline & 0.1 & $106.7(0.5)$ & 0.005 & 0.015 \\
\hline & 0.2 & $99.4(0.4)$ & & \\
\hline \multirow[t]{3}{*}{ FMC } & 0.05 & $101.1(1.4)$ & & \\
\hline & 0.1 & $109.5(0.5)$ & 0.005 & 0.015 \\
\hline & 0.2 & $107.1(0.4)$ & & \\
\hline \multirow[t]{3}{*}{ MF } & 0.05 & $91.7(1.3)$ & & \\
\hline & 0.1 & $106.9(0.8)$ & 0.005 & 0.015 \\
\hline & 0.2 & $101.8(0.6)$ & & \\
\hline \multirow[t]{3}{*}{ 5-HMF } & 0.05 & $99.9(1.8)$ & & \\
\hline & 0.1 & $102.3(1.2)$ & 0.015 & 0.05 \\
\hline & 0.2 & $103.2(0.3)$ & & \\
\hline \multirow[t]{3}{*}{ Furosine } & 0.08 & $84.2(0.10)$ & & \\
\hline & 0.82 & $78.2(0.13)$ & & \\
\hline & 1.63 & $85.2(0.02)$ & 0.02 & 0.06 \\
\hline
\end{tabular}

Note: The unit of the spiked level and the LOD for furosine was $\mathrm{mg} / \mathrm{L}$. 
spectrum methods because of the high sensitivity. However, there is an important factor affecting the determination accuracy, which is always ignored when using MS methods (Gaspar and Lopes, 2009; Truzzi et al., 2012). It is well known that the matrix components can influence the analytes signal, which are called matrix effects, and can mainly influence the quantitation of the GC-MS method. The co-elution of the matrix compounds may reduce or enhance the ion intensity of the target analytes and affect the reproducibility and trueness of the method. Several factors can explain this, such as the features of the analytes, different types of matrices, and the analytes-to-matrix ratio. Many methods can compensate for the matrix effects, including the preparation of matrix-matched standard solutions, multiple purification, standard addition method, analysis of covariance correction, and more. In this study, liquid milk samples and flavored fermented milk samples without target objects were selected for the evaluation of the matrix effects. We made matrix-matched solutions of different concentration levels using the aforementioned extraction solvents of the two matrices and compared the slopes of the standard curves of the solvent and the matrix. Table 2 shows the results.

According to the formula reported by Cui et al. (2020), it can be noted that obvious matrix inhibition effects were observed for furfurals in pure milk and flavored fermented milk samples. Although the matrix effects were always evaluated when using the MS method, we also evaluated for furosine detected by HPLC. There was no significant difference for furosine; thus, the optimized hydrolysis method can effectively remove complex matrix interferences for furosine. The results showed that the MEs for the four furfural compounds were in the range of $-50 \%<\mathrm{ME}<-20 \%$, indicating that the matrix inhibition effects were moderate. As for the reason as to why the matrix effects of the furfural compounds were different from the reported paper by Cui et al. (2020), the explanation might be that, in this paper, the GC-MS technology was used while tandem mass spectrometry had a strong resistance to matrix interference as is well known.

\section{Evaluation of measurement uncertainty}

The uncertainty is because of the existence of the measurement error, which can be used to characterize or measure the degree of uncertainty to the measured value. In the paper, the measurement uncertainty of 5-HMF in the charcoal-flavored fermented milk samples (sample E5) using the GC-MS method has been evaluated, and the measurement uncertainty of furosine in charcoal-flavored fermented milk using the HPLC method has also been evaluated. The mathematical model of measurement was set up, the different parts of uncertainty were analyzed, and the combined standard uncertainty and expanded uncertainty of the measurement results were calculated. We estimated the uncertainty by using the data derived from the validation of the method, including trueness and the repeatability of the experiments. A coverage factor ( $k$ ) was set as 2, representing an expanded uncertainty at the $95 \%$ confidence interval and confirming the reliability of the validated method. Based on the quantitative analysis of each source, the relative standard uncertainty of the measurement results was finally obtained as follows: the determination result of the 5-HMF content in the charcoal-flavored fermented milk was $0.051 \mathrm{mg} / \mathrm{kg}$, and the combined standard measurement uncertainty was $0.0007 \mathrm{mg} / \mathrm{kg}$, so the expanded uncertainty of 5 -HMF was $0.051 \pm 0.0014 \mathrm{mg} / \mathrm{kg}(\mathrm{k}=2)$. The determination result of the furosine content in charcoal-flavored fermented milk was $593.2 \mathrm{mg} / 100 \mathrm{~g}$ protein, the combined standard measurement uncertainty was $2.6 \mathrm{mg} / 100 \mathrm{~g}$ protein, and the expanded uncertainty of furosine was $593.2 \pm 5.2 \mathrm{mg} / 100 \mathrm{~g}$ protein $(\mathrm{k}=2)$. The evaluation indicated that the repetitive test was the main reason for relatively combined standard measurement uncertainty. The influence of the standard solutions could not be neglected. The effect of sample weight was minimal. This evaluation has provided a theoretical basis for the quality control on 5-HMF and furosine contents determination of milk products.

\section{Application-determination of milk samples}

A total of 29 market samples of milk-based dairy products were analyzed using GC-MS and HPLC methods, and most of the samples were liquid milk samples, including 24 samples of liquid packed milk and five fermented milk and milk drink samples; the results are shown in Table 4. The chromatogram of sample E5 is shown in Figure 2B. Among all samples, the $\mathrm{F}$ contents ranged from 0.050 to $0.204 \mathrm{mg} / \mathrm{kg}$, the MF contents ranged from 0.018 to $0.045 \mathrm{mg} / \mathrm{kg}$, the FMC contents were from 0.016 $\mathrm{mg} / \mathrm{kg}$ to $0.048 \mathrm{mg} / \mathrm{kg}$, and the contents of 5-HMF were up to $0.051 \mathrm{mg} / \mathrm{kg}$. The results showed that $\mathrm{F}$ was the most frequently detected compound among furfurals; 5-HMF was not detected in these liquid milk samples, which maybe because their contents were lower than the detection limit. There was an obvious difference between liquid milk samples and fermented milk and milk drink samples; most of the furfurals' detection values of liquid products were below limits of quantitation, while five original-flavored fermented milks were detected of furfurals.

It is well known that, in the process of sterilization, acid hydrolysis will occur and furosine will be produced, and the content level of furosine directly affects the nutrients in milk products. The content of furosine in the 
Table 4. Market samples analysis results of furfural compounds and furosine.

\begin{tabular}{|c|c|c|c|c|c|c|}
\hline \multirow[t]{2}{*}{ Number } & \multirow[t]{2}{*}{ Product type } & \multicolumn{5}{|c|}{ Contents } \\
\hline & & $\begin{array}{c}\mathrm{FU}(\mathrm{mg} / 100 \mathrm{~g} \\
\text { protein) }\end{array}$ & $\begin{array}{c}F \\
(\mathrm{mg} / \mathrm{kg})\end{array}$ & $\begin{array}{c}\text { FMC } \\
(\mathrm{mg} / \mathrm{kg})\end{array}$ & $\begin{array}{l}5-\mathrm{HMF} \\
(\mathrm{mg} / \mathrm{kg})\end{array}$ & $\begin{array}{c}\text { MF } \\
(\mathrm{mg} / \mathrm{kg})\end{array}$ \\
\hline A1 & Low temperature pasteurized fresh skimmed milk & 15.7 & $<L O Q$ & ND & $<L O Q$ & 0.018 \\
\hline $\mathrm{A} 2$ & Low temperature pasteurized pure milk & 13.9 & $<L O Q$ & ND & ND & ND \\
\hline A3 & Low temperature pasteurized fresh organic milk & $<L O Q$ & $<L O Q$ & ND & ND & $<L O Q$ \\
\hline A4 & Low temperature pasteurized fresh casein milk & $<L O Q$ & $<L O Q$ & ND & ND & $<L O Q$ \\
\hline A5 & Low temperature pasteurized fresh milk & 20.1 & $<L O Q$ & ND & ND & ND \\
\hline A6 & Low temperature pasteurized fresh milk & $<L O Q$ & ND & ND & ND & ND \\
\hline A7 & Low temperature pasteurized bright double pure milk & $<L O Q$ & $<L O Q$ & $<L O Q$ & $<\mathrm{LOQ}$ & ND \\
\hline A8 & Low temperature pasteurized pure milk & $<L O Q$ & $<L O Q$ & $<L O Q$ & ND & ND \\
\hline A9 & Low temperature pasteurized pure milk & 21.3 & 0.104 & 0.044 & $<\mathrm{LOQ}$ & $<L O Q$ \\
\hline B1 & High temperature pasteurized whole fat milk & 213.7 & $<L O Q$ & ND & ND & $<L O Q$ \\
\hline B2 & High temperature pasteurized pure milk & 170.8 & ND & ND & ND & $<L O Q$ \\
\hline B3 & High temperature pasteurized pure milk & 211.0 & $<L O Q$ & ND & ND & ND \\
\hline B4 & High temperature pasteurized high calcium milk & 193.6 & $<L O Q$ & ND & ND & ND \\
\hline B5 & High temperature pasteurized concentrated milk & 181.9 & $<L O Q$ & ND & ND & ND \\
\hline B6 & High temperature pasteurized pure milk & 161.9 & $<L O Q$ & $<L O Q$ & $<\mathrm{LOQ}$ & ND \\
\hline $\mathrm{C} 1$ & Ultra-high temperature sterilization whole fat & 300.4 & $<L O Q$ & ND & ND & 0.035 \\
\hline $\mathrm{C} 2$ & Ultra-high temperature sterilization whole fat & 330.3 & $<L O Q$ & ND & ND & $<\mathrm{LOQ}$ \\
\hline D1 & Ultra-high temperature sterilization whole fat high calcium milk & 377.2 & $<L O Q$ & ND & $<\mathrm{LOQ}$ & $<L O Q$ \\
\hline D2 & Ultra-high temperature sterilization milk & 224.7 & $<L O Q$ & ND & ND & $<L O Q$ \\
\hline D3 & Ultra-high temperature sterilization milk & 302.5 & $<L O Q$ & ND & ND & ND \\
\hline D4 & Ultra-high temperature sterilization low fat and high calcium milk & 261.0 & $<\mathrm{LOQ}$ & ND & ND & ND \\
\hline D5 & Ultra-high temperature sterilization pure milk & 221.4 & $<L O Q$ & ND & ND & ND \\
\hline D6 & Ultra-high temperature sterilization pure milk & 243.2 & $<L O Q$ & ND & ND & ND \\
\hline D7 & Ultra-high temperature sterilization pure milk & 271.7 & $<L O Q$ & ND & ND & ND \\
\hline E1 & Original-flavored fermented milk & 267.6 & 0.144 & $<L O Q$ & $<\mathrm{LOQ}$ & ND \\
\hline E2 & Original-flavored milk drink & 548.8 & 0.123 & 0.048 & $<\mathrm{LOQ}$ & ND \\
\hline E3 & Flavored fermented milk & 391.8 & 0.204 & 0.016 & $<\mathrm{LOQ}$ & $<L O Q$ \\
\hline E4 & Flavored fermented milk & 486.6 & 0.05 & $<L O Q$ & $<\mathrm{LOQ}$ & ND \\
\hline E5 & Charcoal-flavored fermented milk & 593.2 & 0.128 & 0.019 & 0.051 & 0.045 \\
\hline
\end{tabular}

low temperature pasteurized (heat temperature lower than $70^{\circ} \mathrm{C}$ ) milk samples was low (milk samples A1-A9), and the differences were not significant among fresh skimmed milk and fresh casein milk. These milk products were prepared through the sterilization of raw milk by low temperature and a long pasteurization time (62$65^{\circ} \mathrm{C}, 30 \mathrm{~min}$ ) or a high temperature short-term pasteurization $\left(72-75^{\circ} \mathrm{C}, 15-20 \mathrm{~s}\right)$. However, we observed that the content of furosine in ultra-high temperature (UHT, $137^{\circ} \mathrm{C}, 4 \mathrm{~s}$ ) milk was higher than that in pasteurized milk because of the higher treatment temperature. Therefore, furosine can be used as the main indicator to distinguish pasteurized milk from UHT milk. To investigate whether fermentation contributes to the production of furosine, original-flavored fermented milk and charcoal-flavored fermented milk samples were analyzed. The results from samples E1 to E5 revealed that the concentrations of furosine in fermented milk samples were higher than those in liquid milk samples. The highest detection value of furosine was $593.2 \mathrm{mg} / 100 \mathrm{~g}$ protein in charcoal-flavored fermented milk, which can be due to the complex production process - a preheat process of $55-80^{\circ} \mathrm{C}$ at first, and then sterilization $\left(120^{\circ} \mathrm{C}\right.$ for $2 \mathrm{~min}$, or $90-95^{\circ} \mathrm{C}$ for 5-10 $\mathrm{min}$ ), natural cooling, and fermentation for 4-5 $\mathrm{h}$ at approximately $45^{\circ} \mathrm{C}$.

Furosine is regarded as an important index to judge the quality of milk. A lower content of furosine may mean better nutritional quality of dairy products (Wang et al., 2019). According to these experiments, the order of milk quality-mainly based on furosine contents-was as follows: Low temperature pasteurized fresh milk > Low temperature pasteurized pure milk > High temperature pasteurized pure milk $>$ Ultra-high temperature 
sterilization whole fat $>$ Ultra-high temperature sterilization pure milk > Original-flavored fermented milk > Flavored fermented milk > Original-flavored milk drink > Charcoal-flavored fermented milk. We can summarize that the Maillard reaction occurs during the heating and fermenting processes which can produce hazardous furfural derivatives and furosine. This result reveals that the heating temperature and fermentation processes are responsible for furosine and furfurals production.

\section{Application-heat-treatment analysis}

Based on the above experimental results, in order to further study the application of the established method, we designed the simulation system experiment, and the process was described in the "sample selection and collection heat treatment" part. We accurately weighed $2.0 \mathrm{~mL}$ samples for the determination of furosine, and the concentrations were expressed in units of $\mathrm{mg} / \mathrm{L}$ instead of $\mathrm{mg} / 100 \mathrm{~g}$ protein. The purpose of this part was to investigate the trends of furosine under different temperatures and times, and the results are shown in Figure 3.

According to reported papers, we observed a change in the content 5-HMF under different temperatures and times (Ahmadian-Kouchaksaraei et al., 2015; Zhang et al., 2021). In addition, the 5-HMF content ranged between $0.046 \mathrm{mg} / \mathrm{kg}$ and $0.886 \mathrm{mg} / \mathrm{kg}$ at different processing temperatures of $25^{\circ} \mathrm{C}-100^{\circ} \mathrm{C}$. No clear trend was observed at $25^{\circ} \mathrm{C}$. The 5 - HMF content increased during heating at $40^{\circ} \mathrm{C}, 60^{\circ} \mathrm{C}, 80^{\circ} \mathrm{C}$, and $100^{\circ} \mathrm{C}$. High temperatures increased the 5-HMF formation rate, which was $0.0007 \mathrm{mg} / \mathrm{kg}$ per min at the processing temperature of $60^{\circ} \mathrm{C}$ and $80^{\circ} \mathrm{C}$, only a little higher than that of $0.0006 \mathrm{mg} / \mathrm{kg}$ per min at a temperature of $40^{\circ} \mathrm{C}$. The formation rate of 5 -HMF was increased to $0.005 \mathrm{mg} / \mathrm{kg}$ per min under the heating temperature of $100^{\circ} \mathrm{C}$, and maximum 5-HMF content was $0.886 \mathrm{mg} / \mathrm{kg}$ after heating for $180 \mathrm{~min}$ at $100^{\circ} \mathrm{C}$. This revealed that the temperature greatly affected the content of 5-HMF, especially when the temperature was higher than $100^{\circ} \mathrm{C}$.

It is well known that the content of furosine is very high when the processing temperatures are high (Ferrer et al., 2003). The objective of the present study was to evaluate both the effect of low and high heating temperatures on furosine in raw materials of milk products. The detected contents of furosine ranged between $0.5 \mathrm{mg} / \mathrm{L}$ and 55.4 $\mathrm{mg} / \mathrm{L}$ at different processing temperatures of $25^{\circ} \mathrm{C}, 40^{\circ} \mathrm{C}$, $60^{\circ} \mathrm{C}, 80^{\circ} \mathrm{C}$, and $100^{\circ} \mathrm{C}$. Maximum furosine content was observed after heating for $150 \mathrm{~min}$ at $80^{\circ} \mathrm{C}$. Furosine contents also increased during heating at $40^{\circ} \mathrm{C}, 60^{\circ} \mathrm{C}, 80^{\circ} \mathrm{C}$, and $100^{\circ} \mathrm{C}$, but no clear trend was observed at $25^{\circ} \mathrm{C}$. High temperatures increased the furosine formation rate, which was $0.217 \mathrm{mg} / \mathrm{L}$ per min at the processing temperature of $60^{\circ} \mathrm{C}$, only a little higher than that of 0.214 $\mathrm{mg} / \mathrm{L}$ per min at $40^{\circ} \mathrm{C}$. However, when the heating temperatures were $80^{\circ} \mathrm{C}$ and $100^{\circ} \mathrm{C}$, the formation of furosine was not straight up; the maximum values were $55.0 \mathrm{mg} / \mathrm{L}$ after heating for $60 \mathrm{~min}$ at $100^{\circ} \mathrm{C}$ and $55.4 \mathrm{mg} / \mathrm{L}$ after heating for $150 \mathrm{~min}$ at $80^{\circ} \mathrm{C}$. We can conclude that when

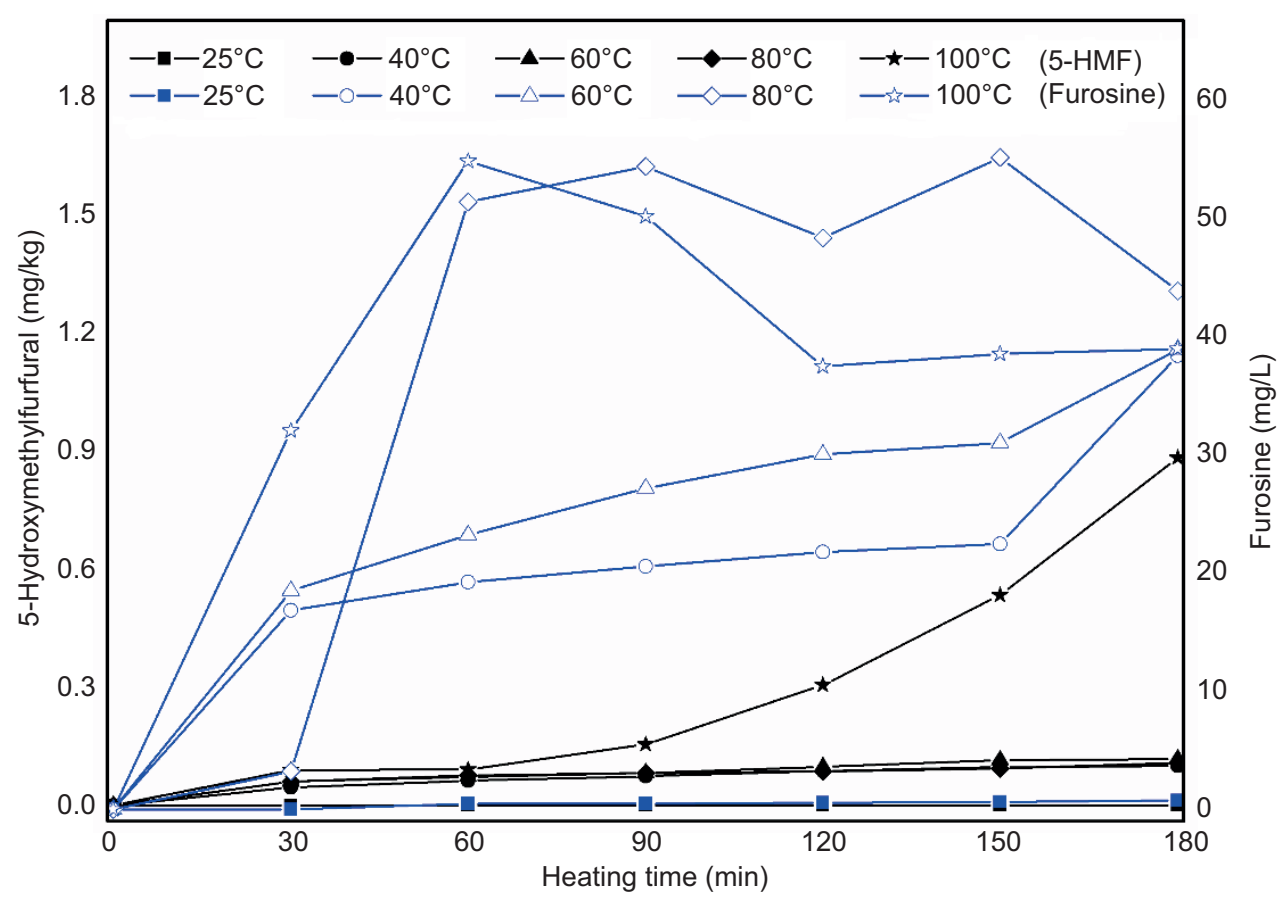

Figure 3. The formation trends under different temperatures and time of furosine and 5-HMF. 
heating times were longer than $120 \mathrm{~min}$, the production of furosine decreased at high temperatures of $80^{\circ} \mathrm{C}$ and $100^{\circ} \mathrm{C}$.

Based on the aforementioned experimental data of the sugar-protein simulation system, we further analyzed the formation stage of furosine and 5-HMF under different temperatures and time. There was no regular pattern to the furosine data; however, the variation of 5-HMF content in the simulated system was first-order kinetics under the process temperatures of $80^{\circ} \mathrm{C}$ and $100^{\circ} \mathrm{C}$, and there were statistically significant differences between temperatures and treatment time within the same temperature. In comparing the concentrations of 5-HMF and furosine formed during the heat treatment, the furosine formation is faster than 5-HMF in all of the samples. In general, the concentration of furosine increased with time and the increase of temperature, but when the processing temperatures were $80^{\circ} \mathrm{C}$ and $100^{\circ} \mathrm{C}$, the formation of furosine was less dependent on temperature than that of 5-HMF, because the content of the furosine was almost the same at $180 \mathrm{~min}$ under different temperature conditions of $40^{\circ} \mathrm{C}, 60^{\circ} \mathrm{C}$, and $100^{\circ} \mathrm{C}$, while the content of 5-HMF always increased under high temperatures of $100^{\circ} \mathrm{C}$.

During the distribution of 5-HMF and furosine at different stages of the Maillard reaction, when the heating temperature is below $100^{\circ} \mathrm{C}$ and the heating time is less than $90 \mathrm{~min}$, the content of furosine is high, which indicates the primary Maillard reaction stage. When the heating temperature is higher than $100^{\circ} \mathrm{C}$, the concentration of 5-HMF increases with a longer heating time, and additional furfural hazards will be generated from the Maillard reaction. This study revealed that furosine and 5-HMF may be useful indicators of the processing conditions of dairy products. Furosine was the indicator for the initial stage of the Maillard reaction, and 5-HMF was an indicator for the middle stage of the Maillard reaction (Lan et al., 2010; Pérez-Burillo et al, 2019; Rada-Mendoza et al., 2004).

\section{Conclusion}

In the present study, a modified QuEChERS method coupled with GC-MS was used to detect the contents of F, MF, FMC, and 5-HMF in milk-based products. For the HPLC analysis of furosine, the optimal hydrolysis time was $18 \mathrm{~h}$ for milk samples. The procedures were simple, rapid, and demonstrated good repeatability, linearity, and sensitivity, and were successfully applied for the determination of 5-HMF and furosine in milk samples. The high concentrations of furosine and 5-HMF were $0.051 \mathrm{mg} / \mathrm{kg}$ and $593.2 \mathrm{mg} / 100 \mathrm{~g}$ protein, respectively, in charcoal-flavored fermented milk, which indicated more attention should be paid to the milk quality. This study announced that the formation of both 5-HMF and furosine is closely related to temperature and time. The formation of 5-HMF is more closely related to high temperatures, while the production of furosine decreased at high temperatures of $80^{\circ} \mathrm{C}$ and $100^{\circ} \mathrm{C}$. The dairy industry should effectively control the temperature and duration of heat treatment and fermentation during the production of milk products.

\section{Acknowledgements}

This work was supported by the National Key R\&D Program of China (No. 2017YFC1600404) is gratefully acknowledged.

\section{Author Contributions}

Y.F.X. and X.M.S. designed the research and conducted the statistical analysis. X.M.S. wrote and reviewed the article, Q.W. participated in the writing of the article and data analysis. D.D.R. and S.Y.W. conducted the research. Y.Z. provided guidance on sentence construction and grammar. All authors have read and approved the final manuscript.

\section{Conflicts of Interest}

The authors report no conflicts of interest.

\section{References}

Abraham, K., Gürtler, R., Berg, K., Heinemeyer, G., Lampen, A. and Appel, K.E., 2011. Toxicology and risk assessment of 5-Hydroxymethyl furfural in food. Molecular Nutrition \& Food Research 55: 667-678. https://doi.org/10.1002/mnfr.201000564

Ahmadian-Kouchaksaraei, Z., Varidi, M., Javad Varidi, M. and Pourazarang, H., 2015. Study of stability characteristics of sesame milk: effect of pasteurization temperature, additives, and homogenisation pressure. Quality Assurance and Safety of Crops \& Foods 7(5): 677-686. https://doi.org/10.3920/ QAS2014.0465

Bignardi, C., Cavazza, A. and Corradini, C., 2012. Determination of furosine in food products by capillary zone electrophoresis-tandem mass spectrometry. Electrophoresis 33: 2382-2389. https:// doi.org/10.1002/elps.201100582

Cattaneo, S., Masotti, F. and Pellegrino, L., 2008. Effects of overprocessing on heat damage of UHT milk. European Food Research and Technology 226: 1099-1106. https://doi.org/10.1007/ s00217-007-0637-5

Chavez-Servin, J.L., Carbot, K., Garcia-Gasca, T., Castellote, A. and Lopez-Sabater, M.C., 2015. Content and evolution of potential 
furfural compounds in commercial milk-based infant formula powder after opening the packet. Food Chemistry 166: 486-491. https://doi.org/10.1016/j.foodchem.2014.06.050

Chávez-Servín, J.L., Castellote, A.I. and López-Sabater, M.C., 2006. Evolution of potential and free furfural compounds in milk-based infant formula during storage. Food Research International 39: 536-543. https://doi.org/10.1016/j.foodres.2005.10.012

Cho, Y.H., Hong, S.M. and Kim, C.H., 2012. Determination of lactulose and furosine formation in heated milk as a milk quality indicator. Food Science of Animal Resources 32: 540-544. https:// doi.org/10.5851/kosfa.2012.32.5.540

Cortés Yáñez, D.A., Gagneten, M., Leiva, G.E. and Malec, L.S., 2018. Antioxidant activity developed at the different stages of Maillard reaction with milk proteins. LWT - Food Science and Technology 89: 344-349. https://doi.org/10.1016/j. lwt.2017.11.002

Cui, Y.Y., Shi, X.M., Tang, Y., Xie, Y.F. and Du, Z.X., 2020. The effects of heat treatment and fermentation processes on the formation of furfurals in milk-based dairy products using a QuEChERS technique followed by gas chromatography coupled with triple quadrupole mass spectrometry. Food Chemistry 313: 125930. https://doi.org/10.1016/j.foodchem.2019.125930

Delgado-Andrade, C., Rufian-Henares, J.A. and Morales, F.J., 2005. Fast method to determine furosine in breakfast cereals by capillary zone electrophoresis. European Food Research and Technology 221: 707-711. https://doi.org/10.1007/ s00217-005-0030-1

Ferrer, E., Alegria, A., Farre, R., Abellán, P. and Romero, F., 2005. High-performance liquid chromatographic determination of furfural compounds in infant formulas during full shelflife. Food Chemistry 89: 639-645. https://doi.org/10.1016/j. foodchem.2004.05.040

Ferrer, E., Alegria, A., Farre, R., Abellán, P., Romero, F. and Clemente, G., 2003. Evolution of available lysine and furosine contents in milk-based infant formulas throughout the shelf-life storage period. Journal of the Science of Food and Agriculture 83: 465-472. https://doi.org/10.1002/jsfa.1402

Gaspar, E.M.S.M. and Lopes, J.F., 2009. Simple gas chromatographic method for furfural analysis. Journal of Chromatography A 1216: 2762-2767. https://doi.org/10.1016/j.chroma.2008.10.049

Giovanelli, G. and Cappa, C., 2021. 5-Hydroxymethyl furfural formation in bread as a function of heat treatment intensity: correlations with browning indices. Foods 10: 417. https://doi. org/10.3390/foods10020417

Gokmen, V. and Senyuva, H.Z., 2006. Improved method for the determination of hydroxymethyl furfural in baby foods using liquid chromatography-mass spectrometry. Journal of Agricultural and Food Chemistry 54: 2845-2849. https://doi.org/10.1021/ jf053091y

Gómez-Narváez, F., Medina-Pineda, Y. and Contreras-Calderón, J., 2017. Evaluation of the heat damage of whey and whey proteins using multivariate analysis. Food Research International 102: 768-775. https://doi.org/10.1016/j.foodres.2017.09.074

Kalal, H.S., Mahani, M.K., Maragheh, M.G. and Chaloosi, M., 2007. HPLC determination of furfural after preliminary extraction to aqueous phase. Journal of Liquid Chromatography \&
Related Technologies 30: 2081-2093. https://doi.org/10.1080/ 10826070701435087

Lan, X.Y., Wang, J.Q., Bu, D.P., Shen, J.S., Zheng, N. and Sun, P., 2010. Effects of heating temperatures and addition of reconstituted milk on the heat indicators in milk. Journal of Food Science 75: 653-658. https://doi.org/10.1111/j.1750-3841.2010.01802.x

Li, Y., Wu, Y.R., Quan, W., Jia, X.D., He, Z.Y., Wang, Z.J., Adhikari, B., Chen, J. and Zeng, M.M., 2021. Quantitation of furosine, furfurals, and advanced glycation end products in milk treated with pasteurization and sterilization methods applicable in China. Food Research International 140(10): 110088. https:// doi.org/10.1016/j.foodres.2020.110088

Liu, H.T., Huang, R.M., Zeng, G.F., Xu, Z.L., Sun, Y.M., Lei, H.T., Sheng, Y.D., Wang, H.M., Xu, B.J. and Wei, X.Q., 2020. Discrimination of reconstituted milk in China market using the content ratio of lactulose to furosine as a marker determined by LC-MS/MS. LWT 117: 108648. https://doi.org/10.1016/j. lwt.2019.108648

Masoumeh, M.T., Marzieh, K. and Abdorreza, M., 2015. Determination of furfural and hydroxymethyl furfural from baby formula using dispersive liquid-liquid microextraction coupled with high performance liquid chromatography and method optimization by response surface methodology. Journal of Food Composition and Analysis 40: 1-7. https://doi.org/10.1016/j. jfca.2014.12.004

Mayer, H.K., Raba, B., Meier, J. and Schmid, A., 2010. RP-HPLC analysis of furosine and acid-soluble beta-lactoglobulin to assess the heat load of extended shelf life milk samples in Austria. Dairy Science \& Technology 90: 413-428. https://doi.org/10.1051/ dst $/ 2009058$

Mesías-García, M., Guerra-Hernandez, E. and García-Villanova, B., 2010. Determination of furan precursors and some thermal damage markers in baby foods: ascorbic acid, dehydroascorbic acid, hydroxyl methyl furfural and furfural. Journal of Agricultural and Food Chemistry 58: 6027-6032. https://doi. org/10.1021/jf100649z

Pérez-Burillo, S., Jiménez-Zamora, A., Párragab, J., Rufián-Henares, J.A. and Pastoriza, S., 2019. Furosine and 5-hydroxymethyl furfural as chemical markers of tea processing and storage. Food Control 99: 73-78. https://doi.org/10.1016/j.foodcont.2018.12.029

Piñeiro-García, A., González-Alatorre, G., Tristan, F., FierroGonzalez, J.C. and Vega-Díaz, S.M., 2018. Simple preparation of reduced graphene oxide coatings for solid phase micro-extraction (SPME) of furfural to be detected by gas chromatography/mass spectrometry. Materials Chemistry and Physics 213: 556-561. https://doi.org/10.1016/j.matchemphys.2018.04.057

Poojary, M.M., Zhang, W., Greco, I., Gobba, C.D., Olsen, K. and Lund, M.N., 2019. Liquid chromatography quadrupole-Orbitrap mass spectrometry for the simultaneous analysis of advanced glycation end products and protein-derived cross-links in food and biological matrices. Journal of Chromatography A 1615: 460767. https://doi.org/10.1016/j.chroma.2019.460767

Rada-Mendoza, M., Sanz, M.L., Olano, A. and Villamiel, M., 2004. Formation of hydroxymethyl furfural and furosine during the storage of jams and fruit-based infant foods. Food Chemistry 85: 605-609. https://doi.org/10.1016/j.foodchem.2003.07.002 
Sabater, C., Montilla, A., Ovejero, A., Prodanov, M., Olano, A. and Corzo, N., 2018. Furosine and HMF determination in prebioticsupplemented infant formula from Spanish market. Journal of Food Composition and Analysis 66: 65-73. https://doi. org/10.1016/j.jfca.2017.12.004

Sakkas, L., Moutafi, A., Moschopoulou, E. and Moatsou, G., 2014. Assessment of heat treatment of various types of milk. Food Chemistry 159: 293-301. https://doi.org/10.1016/j. foodchem.2014.03.020

Sun, Y., Guan, Z.B., Cai, H.W., Huang, Y.Y., Lin, Y.W. and Hu, X.S., 2017. Highly sensitive method for aldehydes detection: application to furfurals analysis in raisin and bovine milk powder. Analytica Chimica Acta 987: 47-55. https://doi.org/10.1016/j. aca.2017.08.032

Sunds, A.V., Rauh, V.M., Sørensen, J. and Larsen, L.B., 2018. Maillard reaction progress in UHT milk during storage at different temperature levels and cycles. International Dairy Journal 77: 56-64. https://doi.org/10.1016/j.idairyj.2017.08.008

Teixidó, E., Santos, F.J., Puignou, L. and Galceran, M.T., 2006. Analysis of 5-hydroxymethyl furfural in foods by gas chromatography-mass spectrometry. Journal of chromatography A 1135: 85-90. https://doi.org/10.1016/j.chroma.2006.09.023

Tokusoglu, O., Akalin, A.S. and Unal, K., 2006. Rapid high performance liquid chromatographic detection of furosine ( $\varepsilon$-N-2-furoylmethyl L-lysine) in yogurt and cheese marketed in turkey. Journal of food quality 29: 38-46. https://doi. org/10.1111/j.1745-4557.2006.00054.x

Truzzi, C., Annibaldi, A., Illuminati, S., Finale, C., Rossetti, M. and Scarponi, G., 2012. Determination of very low levels of
5-(Hydroxymethyl)-2-furaldehyde (HMF) in natural honey: comparison between the HPLC technique and the spectrophotometric white method. Journal of Food Science 77: C784-C790. https://doi.org/10.1111/j.1750-3841.2012.02782.x

Wang, H., Yang, J., Yang, M. and Ji, W., 2019. Antioxidant activity of Maillard reaction products from a Yak casein-glucose model system. International Dairy Journal 91: 55-63. https://doi. org/10.1016/j.idairyj.2018.12.010

Wherry, B.M., Jo, Y. and Drake, M.A., 2019. Concentration of furfuryl alcohol in fluid milk, dried dairy ingredients, and cultured dairy products. Journal of Dairy Science 102: 3868-3878. https://doi.org/10.3168/jds.2018-15714.

Xing, Q.Q., Fu, X.F., Liu, Z.M., Cao, Q. and You, C.P., 2021. Contents and evolution of potential furfural compounds in milkbased formula, ultra-high temperature milk and pasteurised yoghurt. International Dairy Journal 120: 105086. https://doi. org/10.1016/j.idairyj

Yang, L., Liu, Y.H. and Ruan, R.S., 2012. Rapid determination of 5-hydroxymethyl furfural by ultraviolet spectrophotometry in glucose diphasic hydrolysate. Advanced Materials Research 361-363: 1713-1717. https://doi.org/10.4028/www.scientific. net/AMR.361-363.1713

Zhang, Y.M., Yi, S.N., Lu, J., Pang, X.Y., Xu, X.X., Lv, J.P. and Zhang, S.W., 2021. Effect of different heat treatments on the Maillard reaction products, volatile compounds and glycation level of milk. International Dairy Journal 123: 105182. https:// doi.org/10.1016/j.idairyj.2021.105182 